\title{
Prevention of Intraperitoneal Adhesions and Abscesses by Polysaccharides Isolated From Phellinus spp in a Rat Peritonitis Model
}

\author{
Jae-sung Bae, DVM, PhD, * So-jeo Ahn, DVM, $\ddagger$ Hyunee Yim, MD, PhD, $\S$ \\ Kwang-ho Jang, DVM, PhD, * and Hee Kyung Jin, DVM, PhD广
}

\begin{abstract}
Objective: To assess whether polysaccharides isolated from fungi, Phellinus spp, could reduce the adhesion and abscess formation in a rat peritonitis model.
\end{abstract}

Summary Background Data: Although polysaccharides from Phellinus spp is a well-known material with antiinflammatory properties, little is known regarding its ability to prevent intraperitoneal adhesions. We have assessed the adhesion- and abscess-reducing effect of polysaccharides from Phellinus gilvus (PG) and Phellinus linteus (PL) in a rat peritonitis model.

Methods: In 60 SD rats, experimental peritonitis was induced using the cecal ligation and puncture model (CLP). Animals were randomly assigned to 5 groups; ringer lactate solution (RL group), polysaccharides from PG and PL (PG and PL group), hyaluronic acid (HA group), and carboxymethylcellulose (CMC group). Intraperitoneal adhesions and abscesses were noted at 7 day after CLP. RT-PCR assay for urokinase-type plasminogen activator (uPA), its cellular receptor (uPAR), tissue-type plasminogen activator (tPA), plasminogen activator inhibitor type 1 (PAI-1), and tumor necrosis factor (TNF)- $\alpha$ was performed to assess the cecal tissue.

Results: Adhesion formation was significantly reduced in PG, PL, CMC, and HA groups $(P<0.001)$ compared with that in RL group. The incidence of abscesses was also significantly reduced in PG and PL groups $(P<0.05)$ compared with that in the RL group. The level of uPA, uPAR, tPA, and TNF- $\alpha$ was highly expressed in PG and PL group, as compared with the RL group.

Conclusions: We concluded that PG and PL had significant adhesion- and abscess-reducing effects and may act by modulating

From the *Department of Surgery, College of Veterinary Medicine, and $\dagger$ Department of Laboratory Animal Medicine, Pain and Neural Injury Research Center, MRC Kyungpook National University, Daegu, Korea; $\ddagger$ Department of Veterinary Medicine, Kangwon National University, Chunchon, Korea; and the §Department of Pathology, Ajou University School of Medicine, Suwon, Korea.

This work was supported by the Korea Research Foundation Grant (KRF2003-003-E00244).

Reprints: Dr. Hee Kyung Jin, College of Veterinary Medicine, Kyungpook

National University, Daegu, Korea 702-701. E-mail: hkjin@mail.knu.ac.kr. Copyright (C) 2005 by Lippincott Williams \& Wilkins

ISSN: 0003-4932/05/24103-0534

DOI: $10.1097 / 01$. sla.0000154281.79639.89 fibrinolytic capacity of UPA and/or tPA produced from macrophages in a rat peritonitis model.

(Ann Surg 2005;241: 534-540)

ntraperitoneal infection is accompanied by fibrin deposition in the abdominal cavity. This fibrin deposition may lead to clinically significant abscess and adhesion formation. ${ }^{1,2}$ Therefore, degradation of fibrin is a significant target in preventing adhesion formation. Fibrin is degraded by the fibrinolytic system through the action of plasmin, which is enzymatically converted from plasminogen. The conversion is activated directly by tissue-type plasminogen activator (tPA) and urokinase-type plasminogen activator (uPA). ${ }^{3,4}$ Various cells produce tPA, including endothelial cells, mesothelial cells, and macrophages. UPA is produced by the same cells and is equally effective in the degradation of fibrin. ${ }^{5}$

Numerous agents have been investigated in the prevention of adhesions, eg, dextran, corticosteroids, phosphatidylcholine, phospholipase inhibitors, noninflammatory drugs, and tissue plasminogen activator. ${ }^{6,7}$ The capacity of polyanionic polysaccharides, hyaluronic acid (HA) and carboxymethylcellulose $(\mathrm{CMC})$ solution to prevent the formation of postsurgical adhesions in the peritoneal cavity is well documented. ${ }^{8,9}$ It has been demonstrated that polyanionic polysaccharides, such as HA might reduce adhesions and abscesses by modulating fibrinolytic capacity of tPA and uPA produced from endothelial cells, mesothelial cells, and macrophages in peritoneal tissue. ${ }^{10}$ Recently, it was reported that polysaccharides are capable of reducing the frequency of adhesion by preventing with $\beta$-glucanase. ${ }^{11}$ However, the role of polysaccharides in preventing adhesion-related fibrinolytic activity has not been demonstrated to date. In addition, there is little information available concerning the ability of a polysaccharides solution isolated from Phellinus 
spp. such as Phellinus gilvus (PG) and Phellinus linteus (PL) to prevent intraperitoneal adhesion in rats.

PG and PL are fungi belonging to the Hymenochaetaceae basidiomycetes. ${ }^{12}$ It is well known that a polysaccharide solution isolated from these fungi has different medicinal effects such as antitumor, ${ }^{13}$ immunostimulating, ${ }^{14}$ and antiinflammatory activity. ${ }^{15-17}$ The antiinflammatory activities of a polysaccharide solution isolated from PG and PL suggest that these natural products may be beneficial in the treatment of intraperitoneal adhesion related to inflammation. Therefore, in this study, we hypothesize that intraperitoneal abscesses and adhesions could be decreased by modulating fibrinolytic capacity of UPA or tPA using a polysaccharide solution isolated from PG and PL. Here, we investigated whether a polysaccharide solution isolated from PG and PL can reduce the adhesion and abscess formation compared with $\mathrm{HA}$ and $\mathrm{CMC}$, to investigate the fibrinolytic pathway hypothesis in a rat peritonitis model.

\section{MATERIALS AND METHODS}

\section{Preparation of Materials}

The fruiting body of PG was kindly provided by Gyeongbuk Agricultural Technology Administration (Daegu, Korea). To obtain fruiting bodies of PG, a culture was grown in oak sawdust block consisting of $90 \%$ oak and $10 \%$ rice bran for 90 days. ${ }^{18}$ PL was developed for 3 years in routine artificial mulberry cultures and purchased from Sanwhang Mushroom Co (Andong, Korea). The fruiting body of PG and PL was homogenized, extracted by optimal water extraction conditions, distilled water $(1: 25)$ at $100^{\circ} \mathrm{C}$ for 10 hours, and concentrated at $80^{\circ} \mathrm{C}$ in a rotary evaporator. The recovery procedure of the polysaccharide solution from the fruiting body of PG and PL followed previous established methods. ${ }^{19,20}$ The concentration of polysaccharide solutions was determined by measuring total sugar by the anthrone method with glucose as the standard material. ${ }^{21}$

The $0.2 \% \mathrm{HA}$ and $1.7 \% \mathrm{CMC}$ was prepared by adding distilled water at HA (HYAL, Shinpoong Pharm. Co, Korea) and CMC (Sigma Chemical). They were filtered through a $0.22-\mu \mathrm{m}$ membrane filter. All the materials were stored at $4^{\circ} \mathrm{C}$ until used.

\section{Study Design}

Sixty male Sprague-Dawley rats (Charles River Korea Inc., Bio Genomics, Korea) weighing 256 to $274 \mathrm{~g}$ were acclimated for 1 week before the experiments. They were housed in controlled room (temperature: $23 \pm 3^{\circ} \mathrm{C}$, relative humidity: $50 \pm 10 \%$, air circulating frequency: 13-17 times/ hour, artificial light: 300 Lux from 8:00 AM to 8:00 PM, noise: $<50 \mathrm{db})$ and given standard rat chow. Bacterial peritonitis was induced by performing a CLP procedure according to
Wichterman et al. ${ }^{22}$ Only water was provided in the 12 hours preceding the experiments. The animals were weighed and anesthetized by intramuscular injection of a combination of $100 \mathrm{mg} / \mathrm{kg}$ of ketamine hydrochloride (Ketamine, Yuhan Co, Korea) and $5 \mathrm{mg} / \mathrm{kg}$ of xylazine hydrochloride (Rompun, Bayer Korea Ltd, Korea). They breathed spontaneously throughout the procedures. The abdominal skin was disinfected with $70 \%$ alcohol. All procedures were performed under sterile conditions. Routine midline celiotomy was performed with a $3-\mathrm{cm}$ incision, and the cecum was exposed. The cecum was ligated just distally to ileocecal valve with a 3-0 polyglactin 910 (Vicryl; Ethicon, Inc; Johnson \& Johnson Co, Cornelia, CA) suture to avoid intestinal obstruction, punctured once with a 19-gauge needle, squeezed gently to force out a small amount of feces, and then returned to the abdominal cavity. After closing the abdomen in 2 layers with 3-0 polyglactin 910 sutures, the animals received $1 \mathrm{mg} / \mathrm{kg}$ of enrofloxacin (Baytril, Bayer Korea Ltd) and $10 \mathrm{~mL}$ of isotonic sodium chloride solution subcutaneously for analgesia and hydration. After 24 hours, animals were weighed and the abdomen was reopened under the same anesthesia as the first celiotomy. Samples of peritoneal fluid were taken for microbiologic examination. The abdominal cavity was rinsed with $10 \mathrm{~mL}$ isotonic sodium chloride solution, and the cecum was resected. Before closure of the abdomen, the animals were randomly allocated to 5 groups of 12 . One control group was treated intraperitoneally with $8 \mathrm{~mL}$ of Ringer lactate (RL group). Four experimental groups were treated intraperitoneally with $8 \mathrm{~mL}$ of $0.2 \% \mathrm{HA}$ solution (HA group), $1.7 \% \mathrm{CMC}$ solution (CMC group), and $0.25 \%$ polysaccharide solution isolated from PG (PG group) and PL (PL group), respectively. All animals were given water only on the first postoperative day; standard rat chow and water ad libitum were provided on the second postoperative day. The animals were weighed again and killed with carbon dioxide asphyxiation 1 week after the first postoperative day. The abdomen was opened via a U-shaped incision for complete exploration. Adhesions and the incidence of abscesses were examined in a blinded manner by one of us (HK Jin) according to the method of Zuhlke et al, ${ }^{23}$ whereby grade 0 means no adhesions and grade IV means firm extensive adhesions that are dissectible only with sharp instruments, with organ damage almost unavoidable. Sites of adhesions scored included the midline, adnexa/epididymal fat bodies, the upper abdomen (liver), the parietal peritoneum, the omentum, and between the bowel loops. The total score of these 6 locations was noted as the total adhesion score $(0-24)$ (Table 1).

\section{Bacterial Cultures}

Samples of peritoneal fluid and abscesses were taken from all animals on the second postoperative day by swabs for verification of the induced peritonitis. The swabs were immediately introduced into medium and cultured semiquan- 
TABLE 1. Grading of Adhesions According to Zuhlke et al*

\begin{tabular}{ll}
\hline Grade & \multicolumn{1}{c}{ Description } \\
\hline 0 & No adhesions \\
I & $\begin{array}{c}\text { Filmy adhesions: gentle, blunt dissection required to } \\
\text { free adhesions }\end{array}$ \\
II & $\begin{array}{l}\text { Mild adhesions: aggressive blunt dissection required } \\
\text { to free adhesions }\end{array}$ \\
III & $\begin{array}{c}\text { Moderate adhesions: sharp dissection required to } \\
\text { free adhesions }\end{array}$ \\
IV & $\begin{array}{c}\text { Severe adhesions: not dissectible without damaging } \\
\text { organs }\end{array}$ \\
\hline
\end{tabular}

*Locations scored included midline, adnexa/epididymal fat bodies, the upper abdomen (liver), the parietal peritoneum, the omentum, and between the bowel loops. The sum of these locations formed the total adhesion score $(0-24)$.

titatively in aerobic and anaerobic conditions. Samples were incubated on blood and EMB agar for aerobic culture and layered on anaerobic blood agar and incubated in a Gas-Pak jar for anaerobic culture. After 24 and 48 hours of incubation at $37^{\circ} \mathrm{C}$, growing colonies were identified with standard bacteriologic techniques.

\section{Tissue Collection}

The adhesion-carrying cecal site was resected carefully. The cecal tissue was cut longitudinally to remove food contents and washed with sterile phosphate-buffered saline (PBS). Half the tissues in each group were fixed in $10 \%$ formalin in PBS for histopathologic evaluation and the other half in each group was stored at $-80^{\circ} \mathrm{C}$ for RT-PCR analysis until further processing.

\section{Histopathologic Evaluation}

The cecal tissues were fixed in 10\% formalin in PBS for at least 1 hour. After routine tissue processing, serial sections $(5 \mu \mathrm{m})$ were stained with hematoxylin and eosin. The inflammatory reaction was assessed for each group by light microscopy. The grade of inflammation was assessed using a semiquantitative scoring system, the inflammation grading scale. ${ }^{24}$ Grade 1 on this scale represents a mild inflammatory reaction with giant cells, occasional scattered lymphocytes, and plasma cells. Grade 2 represents a moderate reaction with giant cells and increased admixed lymphocytes, plasma cells, eosinophils, and neutrophils. Grade 3 represents a severe inflammatory reaction with microabscesses present.

\section{RNA Extraction}

Total cellular RNA was extracted from rat cecum using a monophasic solution of phenol and guanidine isothiocyanate (TRIzol Reagent, Invitrogen Co, Carlsbad, CA) according to the manufacturer's instructions. The purity and integ- rity of the RNA samples were assessed by $\mathrm{OD}_{260 / 280}$ spectrophotometric measurements.

\section{Reverse Transcription.}

A 1- $\mu \mathrm{g}$ portion of total RNA was subjected to firststrand cDNA synthesis in a $20-\mu \mathrm{L}$ reaction mixture containing moloney murine leukemia virus reverse transcription (10 $\mathrm{U})$, dNTP mixture (2.5-mM concentrations of each dNTP), oligo $(\mathrm{dT})_{12-18}$ primers $(10 \mu \mathrm{M})$, and reaction buffer as supplied with the enzyme $(50 \mathrm{mM}$ Tris- $\mathrm{HCl}, \mathrm{pH} 8.3 ; 50 \mathrm{mM}$ $\mathrm{KCl}, 10 \mathrm{mM} \mathrm{MgCl}_{2}, 0.5 \mathrm{mM}$ spermidine, and $10 \mathrm{mM}$ dithiothreitol). The samples were incubated in a TOUCHgene DNA thermal cycler (Techne (Cambridge) Limited, UK) at $42^{\circ} \mathrm{C}$ for 60 minutes followed by enzyme denaturation step at $94^{\circ} \mathrm{C}$ for 2 minutes. The reverse transcription mixture was stored at $-80^{\circ} \mathrm{C}$ for use in PCR. All reagents were obtained from Promega (Madison, WI).

\section{PCR}

PCR was performed on $2 \mu \mathrm{L}$ of reverse transcription product using Gene Taq (Nippon Gene Co, Ltd, Toyama, Japan) containing TaqDNA polymerase, dNTPs, buffer, and $0.5-\mu \mathrm{M}$ concentrations of each gene-specific forward and reverse primers (obtained from Bioneer, Daejeon, Korea) in a total volume of $50 \mu \mathrm{L}$. Gene-specific oligonucleotide primers were designed from published rat sequences. Primers used for amplification: uPA: sense, 5'-TCGTGAATCAGCCAAAGAAGGAAGAGTACG-3', antisense, 5'-TTACAACTGACATTTTCAGGTCC-3'; uPA receptor: sense, 5'-CAGAACACTGTATTGAAGTGGTGACGCTCC-3', antisense, 5'TCCAAGCACTGATTCATTGGTCCCCG-3'; tPA: sense, 5'-GGCCTGAGGCAATACAAACA-3', antisense, 5'-ATAGCACCCAGCAGGAACTG-3'; plasminogen activator inhibitor type 1 (PAI-1): sense, 5'-AGTCTTTCCGACCAAGAGCA-3', antisense, 5'-CCAGTTTTGTCCCAAAGGAA-3'; tumor necrosis factor (TNF)- $\alpha$ : sense, $5^{\prime}$-TACTGAACTTCGGGGTGATTGGTCC-3', antisense, 5'-CAGCCTTGTCCCTTGAAGAGAACC-3'; glyceraldehyde-3-phosphate dehydrogenase (GAPDH): sense, 5'-TGAAGGTCGGTGTGAACGGATTTGGC-3', antisense, 5'-CATGTAGGCCATGAGGTCCACCAC-3'. The PCR was conducted in TOUCHgene DNA thermal cycler. After an initial denaturation at $95^{\circ} \mathrm{C}$ for 5 minutes, amplification was conducted through 35 cycles of denaturation at $94^{\circ} \mathrm{C}$ for 30 seconds, annealing at $58^{\circ} \mathrm{C}$ (GAPDH) or $60^{\circ} \mathrm{C}$ (for all the other transcripts) for 30 seconds and extension at $72^{\circ} \mathrm{C}$ for 45 seconds. Final extension was at $72^{\circ} \mathrm{C}$ for 10 minutes followed by a final hold at $4^{\circ} \mathrm{C}$. Negative controls (PCR mixture without cDNA) and positive controls (PCR mixture with a standard cDNA sample) were included in preliminary PCR runs. Initial experiments were conducted to determine the optimal annealing temperature for each set of gene-specific primers (data not shown). The PCR products were separated by electrophoresis 
using $2 \%$ agarose gels stained with ethidium bromide to visualize cDNA products.

\section{Statistical Analysis}

Values are expressed as mean \pm SD. Analysis of differences between treated groups and untreated groups was performed using analysis of variance followed by multiple comparisons and Fisher's LSD test using the SAS statistical package (release 8.1; SAS Institute Inc, Cary, NC, USA). Differences at $P<0.05$ were considered statistically significant.

\section{RESULTS}

Following CLP, all rats showed symptoms of peritonitis-like apathetic behavior, ocular exudates, and piloerection. These symptoms resolved within 2 days following the receliotomy and removal of the necrotic, perforated cecum and peritoneal lavage. Survival in all groups was $100 \%$ by the end of the experiment.

\section{Body Weights of the Rats}

The mean \pm SD body weight of the rats was $268.2 \pm$ $5.88 \mathrm{~g}$ at the time of the first operation. The rats lost weight during peritonitis $(259.8 \pm 12.8 \mathrm{~g})$ and recovered weight by the end of the experiment $(260.2 \pm 13.5 \mathrm{~g})$ in RL, HA, and CMC groups. The differences in weight gain were not statistically significant among the groups. But the weight gain in the PG and PL group $(269.2 \pm 11.9 \mathrm{~g})$ was higher than that in the RL, HA, and CMC groups.

\section{Microbiological Examination}

Culture results of the peritoneal fluid taken at the day of cecal resection revealed polymicrobial intraperitoneal infection. The most frequently isolated microorganisms were Escherichia coli (66.7\%), Proteus species (50.3\%), Staphylococcus (44.7\%), Streptococcus (30\%), Gram-positive Bacillus species (9\%), and Klebsiella (3\%). E coli (79.8\%) was the organism isolated most frequently from abdominal abscesses.

\section{Total Adhesion Score and Site of Adhesion}

Rats treated with $0.25 \%$ polysaccharide solution isolated from PG and PL had a significantly lower total adhesion score compared with that of the RL group $(P<0.001)$. The total adhesion score of rats treated with the RL solution was $12.7 \pm 4.8$. Rats treated with $0.2 \%$ of $\mathrm{HA}$ and $1.7 \% \mathrm{CMC}$ were also lower than rats treated RL in total adhesion score $(P<0.001)$. There was no significant difference in total adhesion score among the 4 experimental groups. However, the total adhesion score of the PG group $(2.3 \pm 0.5)$ was slightly lower than that in $\mathrm{HA}(2.7 \pm 0.7), \mathrm{CMC}(3.5 \pm 1.5)$, and PL (3.6 \pm 1.1$)$ groups (Fig. 1). The site of the adhesions did not differ among the groups. Most of the adhesions were found between the bowel loops (78\%), adnexa/epididymal fat

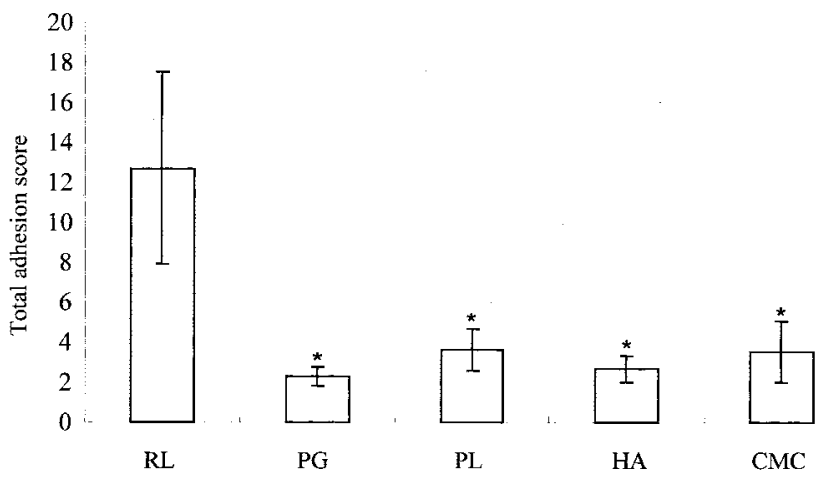

FIGURE 1. Total adhesion score of intraperitoneal adhesion in each group $(\mathrm{n}=12) .{ }^{*} P<0.001$ versus $\mathrm{RL}$ group.

bodies $(69 \%)$, and the omentum $(47 \%)$ in all groups $(P<$ $0.05)$.

\section{Abscesses}

The incidence of intraperitoneal abscess was significantly reduced in rats treated with PG and PL compared with RL ( 0 and 1 of 12 [0\% and 8.3\%] versus 7 of 12 [58\%], $P<$ 0.05 ). Rats treated with HA (3 of 12, 25\%) and CMC ( 2 of 12 , $16.7 \%$ ) had reduced the incidence of abscesses compared with RL ( 7 of 12, 58\%). However, there was no statistical difference in the incidence of intraperitoneal abscesses.

\section{Histologic Evaluation}

Mostly, the inflammatory reaction is dominant at mesenteric fat and serosal surface of cecum. Rats treated with PG demonstrated a markedly reduced inflammatory reaction compared with RL. The RL group showed increased admixed lymphocytes, plasma cells, eosinophils, and neutrophils (grade 3 on the inflammation grading scale) (Fig. 2). The grade of inflammatory response for the PG $(1.2 \pm 0.4)$, PL group $(1.5 \pm 0.5)$, and HA $(1.8 \pm 0.4)$ was significantly lower than grade for the $\mathrm{CMC}(2.5 \pm 0.5)$ and $\mathrm{RL}(2.8 \pm 0.4)$ $(P<0.001)$ (Fig. 3).

\section{The mRNA Expression}

Experiments were carried out to demonstrate the effect of PG and PL on the release of UPA, UPAR, tPA, PAI-1, and TNF- $\alpha$. The $u P A$ and $t P A$ gene expression increased in all groups except the RL group. Conversely, the PAI-1 expression was significantly increased in the RL group. The $u P A R$ mRNA expression was greatly increased in the presence of treatment with $\mathrm{PG}$. In the $\mathrm{PG}, \mathrm{PL}$, and $\mathrm{CMC}$ treatment groups, $T N F-\alpha$ mRNA was highly expressed, as compare with treatment with RL. The GAPDH transcript levels among all groups were the same (Fig. 4). 

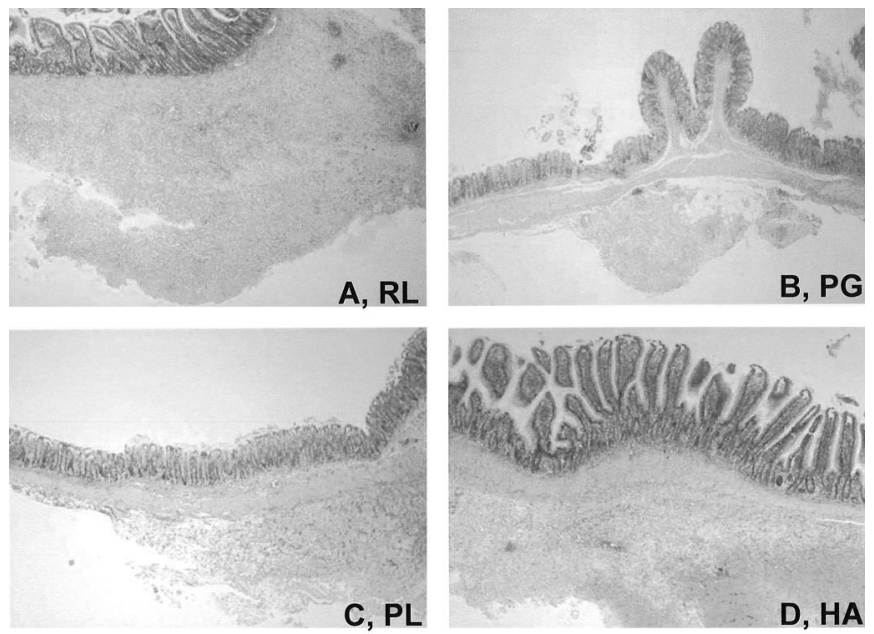

FIGURE 2. Compare the extent of mesenteric inflammatory reaction among $A, R L ; B, P G ; C, P L ;$ and $D, H A(\times 40)$. Note markedly reduced inflammatory reaction in $\mathrm{PG}$-treated groups $(n=6)$.

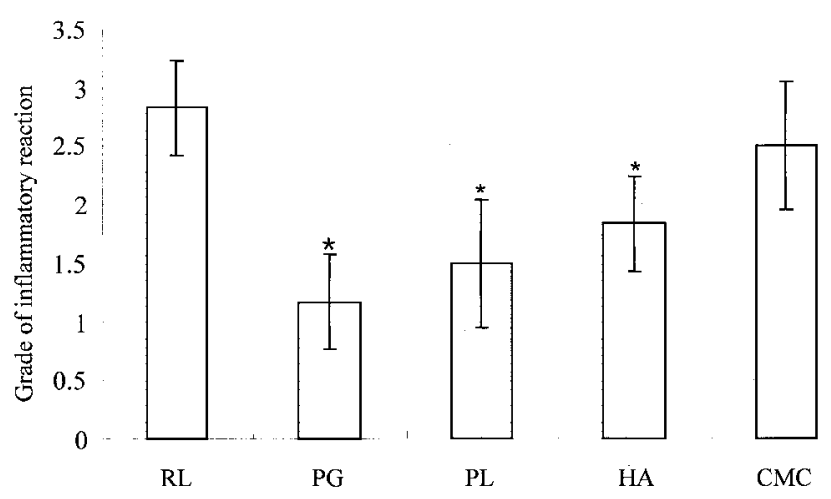

FIGURE 3. The grade of inflammatory reaction in each group $(\mathrm{n}=12) .{ }^{*} \mathrm{P}<0.05$ compared with $\mathrm{RL}$ group.

\section{DISCUSSION}

The use of carbohydrate derivatives in the treatment of adhesion and abscess formation in intraperitoneal infection is not new. Polyanionic polysaccharides, HA, and CMC, as well as $\beta$-glucan in polysaccharides, have been shown to reduce adhesion and abscess formation in a rat peritonitis model. ${ }^{8,11}$ In our study, we treated intraperitoneal adhesions with $8 \mathrm{~mL}$ of $0.2 \% \mathrm{HA}$ and $1.7 \% \mathrm{CMC}$ in a similar manner to Reijnen et $\mathrm{al},{ }^{8}$ who have previously demonstrated that this solution significantly reduces adhesion formation. We investigated the effect of a polysaccharide solutions isolated from the fungi, PG, and PL on intraperitoneal adhesion and abscess formation in rats that underwent cecal resection in the setting of peritonitis.

PL used in our study is well known as one of the most popular medicinal mushrooms due to its high antitumor ${ }^{13}$ and immunostimulating activity. ${ }^{14}$ Recently, it was reported that
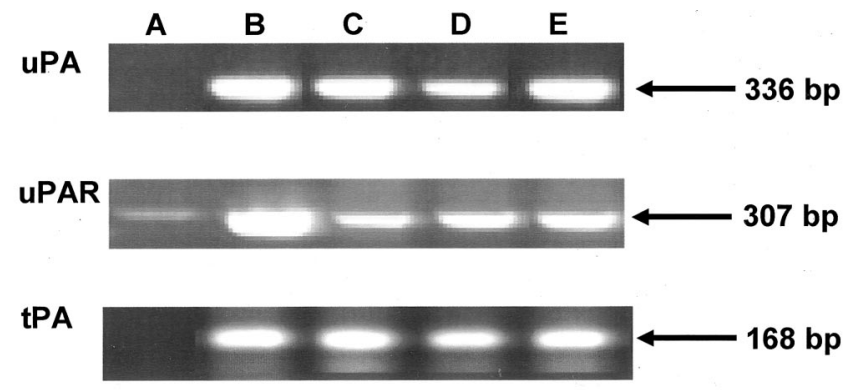

PAl-1

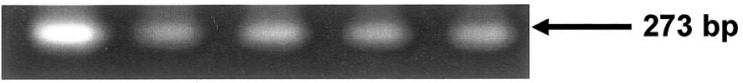

TNF- $\alpha$
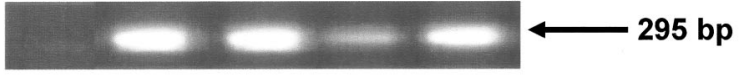

GAPDH

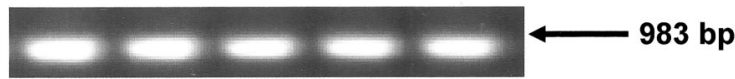

\section{A: RL, B: PG, C: PL, D: HA, E: CMC}

FIGURE 4. UPA, UPAR, $t P A, P A I-1$, and TNF- $\alpha$ mRNA expression in each group $(\mathrm{n}=6)$. The $U P A$ and $T P A$ gene expression was greatly increased in all groups, compared with the RL group. Conversely, PAI-1 expression was significantly increased in the $\mathrm{RL}$ group. The $U P A R$ mRNA expression was greatly increased in the presence of treatment with PG. In the PG, PL, and CMC treatment groups, TNF- $\alpha$ mRNA was highly expressed, as compare with treatment with RL. The GAPDH transcript levels among all groups were the same.

polysaccharide solutions from PL and PG had antiinflammatory activity related to arthritis, septic shock, and pulmonary inflammation. ${ }^{15-17}$ But it was not reported regarding to activity related to prevention of intraperitoneal adhesion by PG and PL. PG has other advantages over PL in that it has a very short growth period (3 months) compared with PL (2-3 years), making it cheaper to produce, and the safety of a single orally administered dose of $\mathrm{PG}$ in rats has been demonstrated. ${ }^{25}$ In the present study, solutions of polysaccharide from both PG and PL significantly decreased adhesion formation. Therefore, this suggests an additional potential therapeutic role for PG in the treatment of inflammation in the future.

In an experimental study, Bedirli et al $^{11}$ showed that $\beta$-glucan in polysaccharides had beneficial effect on the body weight of the animals. In our study, although it is not statistically significant, gain of weight in the PG and PL groups was higher than that in RL, HA, and CMC groups. The precise mechanism of weight gain in these animals is uncertain. We postulate that this could be related to a difference in the mechanism by which adhesion formation is reduced.

Bedirli et $\mathrm{al}^{11}$ also reported that $\beta$-glucan in polysaccharides was capable of reducing the frequency of adhesion 
with $\beta$-glucanase. But in our study, we showed the role of fibrinolytic activity by uPA, UPAR, and IPA in preventing adhesion formation since the $u P A$, its receptor $(u P A R)$, and $t P A$ mRNA expression increased in PG and PL group. Therefore, we think that PG and PL might be reduced adhesions and abscesses by modulating fibrinolytic capacity of uPA, uPAR, and tPA. In addition, we showed increase of PAI-1 mRNA expression in RL group. It also results in increased plasminogen activation by decreasing the extracellular expression of the main inhibitor PAI-1.

TNF- $\alpha$ is a well-known proinflammatory cytokine. Secretion of it increased early in the inflammatory cascade from macrophage and decreased in the latter term. In our study, we demonstrated expression of TNF- $\alpha$ at day 7 after CLP, and it decreased in only RL group. We may think that decrease of TNF- $\alpha$ in RL group is result from expression of latter term in the inflammatory cascade. Many studies also showed that $\beta$-glucan in polysaccharides is a potent stimulator of macrophage functions, and it induces TNF- $\alpha$ production in wound tissue. ${ }^{26,27}$ More recently, Reijnen et al ${ }^{10}$ reported that HA counteracts the fibrinolytic decline induced by TNF- $\alpha$; Boyce et $\mathrm{al}^{28}$ indicated that TNF- $\alpha$ down-regulates fibroblastic collagen synthesis within experimental wounds and HA stimulates TNF- $\alpha$ production by human macrophages. In our study, $T N F-\alpha$ mRNA was highly expressed in the PG and PL groups, as compare with the RL group. This is in accordance with the results from Abel and Czop, ${ }^{27}$ which indicated that $\beta$-glucan induces TNF- $\alpha$ production in wound tissue. In the HA and CMC groups, the level was slightly expressed compared with that of RL group. This is also in accordance with the results from Reijnen et al ${ }^{10}$ and Boyce et al. ${ }^{28} \mathrm{We}$ indicate that polysaccharide solutions isolated from PG and PL stimulate macrophage activity and increased secretion of uPA, tPA, uPAR, and TNF- $\alpha$ by stimulated macrophage activity. Thus, we can conclude that polysaccharide solutions isolated from PG and PL decreased adhesion formation by increasing macrophage activity and enhancing fibrinolytic activity.

In conclusion, polysaccharide solutions isolated from the fungi PG and PL are pharmacologic agents that rapidly enhance host resistance to a variety of biologic insults through the fibrinolytic system, and this involves macrophage activation. In the present study, these polysaccharides significantly decreased intraperitoneal adhesion and abscess formation in a rat peritonitis model. It was as effective as $\mathrm{HA}$ and $\mathrm{CMC}$ in prevention of intraperitoneal adhesion. Additional studies will help determine the optimal concentrations of PG and PL that prevent adhesion formation and help elicit whether the use of such agents in combination may have wider clinical application.

\section{ACKNOWLEDGMENTS}

The authors thank J. K. Lee and S. I. Kim for technical assistance. Thanks are also due to Dr. J. Carter, Department of Psychiatry and Behavioral Sciences, Uni- versity College, for helping with preparation of manuscript, and Dr. S. C. Park, Department of Veterinary Pharmacology, Kyunpook National University, for helping with the provision of PG and PL.

\section{REFERENCES}

1. DeCherney AH, diZerega GS. Clinical problem of intraperitoneal postsurgical adhesion formation following general surgery and the use of adhesion prevention barriers. Surg Clin North Am. 1997;77:671-688.

2. Holmdahl L, Risberg B. Adhesions: prevention and complications in general surgery. Eur J Surg. 1997;163:169-174.

3. Holmdahl L, Ivarsson ML. The role of cytokines, coagulation, and fibrinolysis in peritoneal tissue repair. Eur J Surg. 1999;165:1012-1019.

4. Sulaiman H, Dawson L, Laurent GJ, et al. Role of plasminogen activators in peritoneal adhesion formation. Biochem Soc Trans. 2002;30:126-131.

5. Lu HR, Wu Z, Pauwels P, et al. Comparative thrombolytic properties of tissue-type plasminogen activator (t-PA), single-chain urokinase-type plasminogen activator ( $\mathrm{u}-\mathrm{PA}$ ) and $\mathrm{K} 1 \mathrm{~K} 2 \mathrm{Pu}$ (a t-PA/u-PA chimera) in a combined arterial and venous thrombosis model in the dog. J Am Coll Cardiol. 1992;19:1350-1359.

6. Treutner KH, Bertram P, Lerch MM, et al. Prevention of postoperative adhesions by single intraperitoneal medication. J Surg Res. 1995;59: 764-771.

7. Hill-West JL, Dunn RC, Hubbell JA. Local release of fibrinolytic agents for adhesion prevention. $J$ Surg Res. 1995;59:759-763.

8. Reijnen MM, Skrabut EM, Postma VA, et al. Polyanionic polysaccharides reduce intra-abdominal adhesion and abscess formation in a rat peritonitis model. J Surg Res. 2001;101:248-253.

9. Sawada T, Hasegawa K, Tsukada K, et al. Adhesion preventive effect of hyaluronic acid after intraperitoneal surgery in mice. Hum Reprod. 1999; 14:1470-1472.

10. Reijnen MM, van Goor H, Falk P, et al. Sodium hyaluronate increases the fibrinolytic response of human peritoneal mesothelial cells exposed to tumor necrosis factor alpha. Arch Surg. 2001;136:291-296.

11. Bedirli A, Gokahmetoglu S, Sakrak O, et al. Prevention of intraperitoneal adhesion formation using beta-glucan after ileocolic anastomosis in a rat bacterial peritonitis model. Am J Surg. 2003;185:339-343.

12. Dai YC, Xu MQ. Studies on the medicinal polypore, Phellinus baumii, and its kin, P. linteus. Mycotaxon. 1998;67:191-200.

13. Han SB, Lee CW, Jeon YJ, et al. The inhibitory effect of polysaccharides isolated from Phellinus linteus on tumor growth and metastasis. Immunopharmacology. 1999;41:157-164.

14. Lee JH, Cho SM, Kim HM, et al. Immunostimulating activity of polysaccharides from mycelia of Phellinus linteus grown under different culture conditions. J Microbiol. 1996;6:52-55.

15. Kim GY, Roh SI, Park SK, et al. Alleviation of experimental septic shock in mice by acidic polysaccharide isolated from the medicinal mushroom Phellinus linteus. Biol Pharm Bull. 2003;26:1418-1423.

16. Kim GY, Kim SH, Hwang SY, et al. Oral administration of proteoglycan isolated from Phellinus linteus in the prevention and treatment of collagen-induced arthritis in mice. Biol Pharm Bull. 2003;26:823-831.

17. Jang BS, Kim JC, Bae JS, et al. Extracts of Phellinus gilvus and Phellinus baumii inhibit pulmonary inflammation induced by lipopolysaccharide in rats. Biotechnol Lett. 2004;26:31-33.

18. Jo WS, Rew YH, Kim CB, et al. Development of fruitbody in the artificial oak sawdust cultures of Phellinus gilvus mushroom. Korean $J$ Mycol. 2002;30:109-112.

19. Bae JS, Jin HK, Jang KH. The effect of polysaccharides and carboxylcellulose combination to prevent intraperitoneal adhesion and abscess formation in a rat peritonitis model. $J$ Vet Med Sci. 2004, in press.

20. Kim DH, Yang BK, Jeong SC, et al. Production of a hypoglycemic, extracellular polysaccharide from the submerged culture of the mushroom, Phellinus linteus. Biotechnol Lett. 2001;23:513-517.

21. Bucci SJ, Scholz FG, Goldstein G, et al. Dynamic changes in hydraulic conductivity in petioles of two savanna tree species: factors and mechanisms contributing to the refilling of embolized vessels. Plant, Cell Environ. 2003;26:1633-1645. 
22. Wichterman KA, Baue AE, Chaudry IH. Sepsis and septic shock: a review of laboratory models and a proposal. J Surg Res. 1980;29:189-201.

23. Zuhlke HV, Lorenz EM, Straub EM, et al. Pathophysiology and classification of adhesions. Langenbecks Arch Chir Suppl II Verh Dtsch Ges Chir. 1990;345:1009-1016.

24. Hooker GD, Taylor BM, Driman DK. Prevention of adhesion formation with use of sodium hyaluronate-based bioresorbable membrane in a rat model of ventral hernia repair with polypropylene mesh: a randomized, controlled study. Surgery. 1999;125:211-216.

25. Bae JS, Jang KH, Choi SG, et al. Acute oral toxicity of extract derived from fruiting body of Phellinus gilvus in rats. J Toxicol Pub Health. 2003;19:211-215.

26. Czop JK, Kay J. Isolation and characterization of beta-glucan receptors on human mononuclear phagocytes. J Exp Med. 1991;173:1511-1520.

27. Abel G, Czop JK. Stimulation of human monocyte beta-glucan receptors by glucan particles induces production of TNF-alpha and IL-1 beta. Int J Immunopharmacol. 1992;14:1363-1373.

28. Boyce DE, Thomas A, Hart J, et al. Hyaluronic acid induces tumour necrosis factor-alpha production by human macrophages in vitro. $\mathrm{Br} J$ Plast Surg. 1997;50:362-368. 